\title{
ON ANNE LISE ELLINGS AETER, AN-MAGRITT JENSEN AND MERETE LIE'S, THE SOCIAL MEANING OF CHILDREN AND FERTILITY CHANGE IN EUROPE (2013, ROUTLEDGE/ESA STUDIES IN EUROPEAN SOCIETIES, PP. 188.)
}

KITTI KUTROVÁTZ

The authors of this volume investigate the issue of fertility using a new approach; they do not focus on the causes of the downward trend in births in Europe but they rather pose questions about the decision-making processes that affect the childbearing habits of young adults. The primary questions (namely, why people do have children, and what do these children mean to them?) spur the different lines of inquiry in the book. These questions are based on the following statement: “...our empirical studies of the transition to parenthood in Europe are embedded with the notion of the "social meaning of children" (p. 1). Consequently, the aim of this book is to provide a comprehensive understanding of reproductive choices and shed some light on their diverse and complex nature in Europe through investigating the meaning of children from different approaches and by diverse methods.

This new approach makes it possible to explore important and so-far unknown factors behind the decisions that are made about childbearing, thereby broadening the scope of knowledge about today's fertility trends in Europe. The book's starting conception is therefore very fruitful and relevant.

The editors, Anne Lise Ellingsæter (University of Oslo), An-Magritt Jensen and Merete Lie (Norwegian University of Science and Technology) describe two fertility trends for Europe, both of which require deeper investigation. First, it is suggested that - despite the similarities in the processes of family formation (later first births, more children outside marriage, growing childlessness etc.) - regional variation has increased. These similar, newly-

1 Kitti Kutorvátz is Ph.D. student at the Corvinus University of Budapest; e-mail: kitti.kutrovatz@ gmail.com 
emergent (and deepening) patterns across Europe are not accompanied by the same consequences for national fertility, and different family patterns can also be distinguished. Secondly, while the issue of the fertility crisis dominates the European debate, there are some countries which have witnessed slight increases in childbirth despite the significant participation of women in the labour market. This fact questions the accuracy of the claim that women's new roles - their increasing participation in higher education and in the labour force - explain declines in fertility.

The authors' theoretical perspectives about fertility are based on the intertwined features of the public and the private in reproduction. "In late modern societies rapid transformations in private life are attracting increasing public attention, and recent theories emphasize the interweaving of the private and public. Feelings, bodies, sexualities and ways of thinking are patterned by different social conditions: our most intimate decisions are associated with and shaped by our most public institutions. (p. 4)" They review the Foucaultian concept of biopolitics and examine how reproduction has become dissociated from the private arena and has come to the fore of public interest. On the other hand, they note that sexuality has become disconnected from reproduction. The editors claim that, because of the growing importance of individual choice, societal and individual interests in children may conflict with each other.

In their analytical approach three main elements are highlighted. One of the central components of the book is the notion of the social meaning of children. Based on Viviana Zelizer's ideas, they emphasize the relevance of economic and emotional factors in fertility choices and their embeddedness in a social and cultural context. They thus explore the institutional and relational factors which determine the social meaning of children through a combination of an economic and a cultural approach.

Moreover, gender and social class dimensions are brought into focus. Shared values about good mothering and intensive fathering - in the Nordic countries - or policies designed to promote gender equality may shape the social meaning of children. They also claim that more attention should be paid to men's values and fertility behaviour.

Furthermore, while on one hand they argue that the social class dimension has been neglected in fertility studies, on the other hand they state that its use enables an investigation of the fertility issue from both an economic and a cultural approach since values and ideas may be differentiated across classes.

The book is structured in the following way: it includes twelve chapters, of which the above-described introductory chapter is followed by another ten chapters, each investigating the fertility question from a different perspective, 
employing diverse methods. The book utilises examples from six different nations. The Nordic countries represent the majority: there are four studies about Norway, one about Sweden, and lastly, one about Denmark; all these countries have a relatively high fertility rate and a slight tendency towards population growth. Additionally, there is a paper based on data from France. France is also known for its high fertility rate, but the social and political context is significantly different from that of the Scandinavian countries. Finally, there are studies about Germany and Italy: countries with a very low level of fertility.

Since the aim of this book is to explore and interpret the variety of factors that play a role in individual fertility decisions, micro and macro level analyses and a mix of these approaches is employed. The studies mainly attempt to focus on emotional motives and other non-economic rationales, therefore qualitative methods predominate throughout the research. In the following I provide an overview of the research objectives of the different chapters.

In the second chapter Marie-Thérèse Letablier investigates the social meaning of children at both a micro and a macro level. The author reviews changes in family policies in France using a historical perspective in order to explore how this policy arrangement influences fertility-related intentions. Besides this, current attitudes and values towards parenting and work (and the tension between them) are illustrated through the interpretation of qualitative interviews as regards three different family patterns: traditional families, dual-earners and career-oriented couples.

The next paper, by Ellingsæter and Eirin Pedersen (Chapter 3), addresses the rationales and the role that the welfare state plays in the decision to have a child. The case of Norway is examined. Although fertility (and related to this, the social meaning of children) is approached rather from an economic perspective - the goal is to investigate the importance of economic security the social context is taken into consideration in the investigation into families of different status: upper middle class, and working class. Research is based on semi-structured interviews.

Karin Jurczyk in the fourth chapter examines the impact of flexible working conditions on fertility behaviour using the example of Germany. The research is based on qualitative interviews and is constructed around two areas of investigation: the individual importance of children, and fertility behaviour. An additional two other factors are taken into consideration; namely, the differences between the former East and West Germany, and gender.

The paper applies the concept of blurred boundaries between the two spheres (the public and the private) through examining the changes in working conditions that manifest themselves in increasing demands for flexibility. The 
duality of flexible work is put under the microscope. The research focuses on two different groups with highly flexible working conditions: retail workers and media industry employees.

In the fifth chapter Mai Ottosen and Sofie Skovdal Mouritzen focus on micro-level perspectives in order to explore the role of structural restrictions and normative pressures in decision-making (including timing) about family formation in Denmark. A qualitative, specifically biographical approach is employed in their explorative research. The temporality aspect and the place of agency in structure are the focus, and four life-approaches to relationships and family creation processes among youth aged between their late twenties and late thirties are identified along these concepts. The authors also approach family formation through the lens of emerging adulthood, which refers to the characteristics of a gradual transitional process and defines a separate developmental period.

Malin Noem Ravn and Merete Lie (Chapter 6) investigate the cultural ideal of joint decision making about whether to have a child and address whether couples want to have children, when and how many. Their starting point is based on the cultural ideal of joint decisions and proposes that there is a cultural consensus that the childbearing decision should involve a joint decision by a couple. The research is based on data from semi-structured interviews in Norway. The balance between relational and individual values concerning the timing of childbearing and between gender differences and equality is examined.

In the seventh chapter Disa Bergnéhr and Eva Bernhardt investigate the positive and negative implications of having children in Sweden by using a mixed method research design which included the collection of data from both survey and focus groups. The research focuses on the expected consequences of parenthood. The concept applied is based on the notion that in an individual-centric modern world the child is a symbol of dependence and an obstacle to living a self-centred life. Therefore parenthood has high social value and consequently may lead to ambivalent feelings.

The next chapter (8) is approached by Jensen from a gendered perspective: the starting point of the research is the observation that, despite increases in birth rates over the last three decades in Norway, the number of childless men is also increasing. The author employs a network analysis approach and investigates Granovetter's threshold level and bandwagon effect concepts and Rossie and Bernardi's social learning concept in order to explore the impact of networks on the decision to have children and to understand class and gender differences in this regard. The research is designed to help clarify the position of children in social networks through examining the way individuals 
talk about children.

Trude Lappegård et al. (Chapter 9) examine changes in fertility behaviour by comparing two five year cohorts (born 1945-49 and 1960-64) in Norway. Their research has three main focal areas: fertility, gender and class. They suggest that a changed political and social context-including the contraceptive revolution, abortion legislation, parental leave, day-care facilities, and the increasing proportion of women in higher education - has led to changing gender and class norms and thereby has changed the meaning awarded to having children.

Finally, Laura Bernardi (Chapter 10) approaches fertility issues from an intergenerational perspective. The author investigates mother and their childless daughter dyads in Italy using semi-structured interviews in order to explore the intergenerational transmission of normative beliefs about fertility choices. The research applies an interpretative approach that is focused on the contextualization of values. Differences and similarities in proscriptive and prescriptive norms are taken into consideration. The main issues addressed are the values that relate to the choice of daughters to have children, their number and the timing of childbearing.

In the very last chapter of this book the editors summarize the former content and highlight the important focal points which arise in the different papers, such as the significance of countries' policies towards family or gender equality, the importance of working conditions and their regulation, and the impact of personal relations on fertility behaviour.

Although all the chapters approach the topic from different perspectives, employ diverse methods and pose various research questions in order to contribute to better understanding of the complexity of reproductive choice and of the social meaning of children, there are some core issues which appear throughout the papers. In what follows I review these topics and findings of the different papers in this regard.

First of all, there are three papers (Chapter 2, 3, 4) in which, besides individual behaviour, political and social contexts appear as the objects of investigation. In these papers there is also a strong emphasis on examining the relationship of economic factors to childbearing. Moreover, related to this economic perspective, the importance of family policies and childcare services are outlined. In these chapters there emerges the primary problem of maintaining an appropriate work-life balance.

Letablier argues that pro-natalist family policy in France has created and strongly embedded a societal climate and a social norm that supports having children - even a lot of them - and the foundation of values according to which children are seen as a public matter, and investment in them is of high 
value. Consequently, the informants consider it an obvious decision to have children, and, based on trust in the shared responsibility for childrearing between parents and the state, do not see childbearing as an economic and social risk.

Although France has the highest fertility rate in Europe, accompanied with the greatest economic activity of women, policies - invented within the frame of "liberty of choice" rhetoric - have resulted in the maintenance of traditional gender roles and in the promotion of social inequality. The following statement highlights the mechanisms (namely the opposing interests of pro-family associations and the women's movement) Letablier considers to be responsible for the (paradoxical) French situation: "However, the shift in family policy from support to the direct costs of children to enable reconciling work and family life was trapped in opposite paradigm, namely between familialism supporting the traditional division of labour within the family, and feminism supporting women's emancipation through participation in economic activity" (20. p). The problems are identified as the absence of encouragement or a lack of support for the involvement of the father in parental activities, in insufficient access to childcare facilities for children of less than three years of age, and in growing social inequality due to the horizontal redistribution of parental support.

Similarly to Letablier's findings, Ellingsæeter and Pedersen also propose that the macro context has had high significance for fertility behaviour; however, there are some notable differences between the Norwegian and the French welfare state.

Although it is emphasised that the emotional aspects of having children are of much greater importance than economic considerations (as in the aforementioned paper), economic responsibility appears to be a prerequisite for having children, yet perceived economic security varies by social status and gender. One main pillar of economic responsibility involves having secure employment - principally for women - and thus the existence of the dualearner provider model seems to be crucial in the decision to have children.

Finally, the authors highlight the mitigating effect of family policy; trust in the welfare state is reported on in the interviews and may have had an impact on some of the decisions. The comprehensive and generous family policy and (in contrast to France) universal access to childcare for children of under 3 years of age in Norway - both of which support the dual-earner model - are highly significant. Besides this fact, a strong labour market which manifests itself in high employment rates for both genders, high wages and restrictive regulations on firing and hiring encourages the decision to have children and supports the comparatively high fertility rates in Europe. 
The findings suggest that it is not only economic security but also the possibility - mainly through the existence of childcare institutions - to reconcile family and work life that are crucial. Oláh et al. (2002) ${ }^{2}$ also suggest that the role of the state in childrearing is crucial and determines not only fertility choices but has an impact on gendered family patterns. Therefore the significant role of structural institutions reveals the problems that exist with the work-life balance of young adults. The chapter written by Jurczyk focuses on these difficulties and investigates the impact of flexible working conditions. Hochschild (2001) in her influential study argues that the borders between family and work have become permeable; consequently, the roles of home and work are now reversed. With the growing flexibilization of work this issue has become more relevant than ever. Jurczyk focuses on the two-sided nature of flexibilization; namely, that flexible work may be both advantageous and disadvantageous for family life. Her findings confirm the supposition that the blurring boundaries of work have an ambivalent nature (this phenomenon is also characterized by emotional spill over from paid work to family, which also may render it more difficult to combine work and family life). Moreover, the Fordist time-space pattern which dominates childcare institutions can conflict with the post-Fordist working conditions of parents.

Furthermore, and in contrast to the previous two papers, Jurczyk argues that children are primarily a private matter in Germany; they are therefore perceived as an economic and social risk for parents, especially in West Germany. Accordingly, having a higher income and job status has a positive impact on childbearing, although the greater availability of flexible work has had the greatest influence. She argues that "the social meaning of children is not embedded in the structure or in the culture of work" (p. 63).

Besides structural factors, individual attitudes and values about having children and about parenthood are also underlined in the book (Chapter 5 , 6,7 and 10). The conflict between individual values and having children is central to these analyses. The following chapters pose very similar question to those the informants raise - namely, whether they want to have children, how many children they plan to have and what the right time is for having a

2 Oláh, L. Sz. - Bernhardt E. M. - Goldscheider, F. K. (2002): Coresidential Paternal Roles in Industrialized Countries: Sweden, Hungary and the United States. In Hobson, B. (Ed.): Making man into father. Man, Masculinity and the Social Policies of Fatherhood. Cambridge: Cambridge University Press, 25-57.

3 Hochschild, A. R. (2001): The Time Bind: When Work Becomes Home and Home Becomes Work. New York: Holt Paperbacks 
child - but they approach the questions from diverse theoretical backgrounds and apply different methods.

In the fifth chapter the temporality aspect takes centre stage. Ottosen and Mouritzen conclude that the changing nature of the social meaning of children appears in the fact that a child has become a 'calculated project' instead of natural event in adult life. Their findings outline the importance of the pattern of time orientation, mainly in terms of thinking about and being connected to the future. Furthermore, social position and gender have significance. The highly educated have tended to be more rational about their futures and this has had an impact on their life-management, although women have suffered more from the (biological) pressure to have children at a certain age. Despite the factors listed above, it has been suggested that age norms have the greatest influence in terms of the normative understanding of when the ideal time is to have children. Today in Denmark, this right time seem to be around thirty years of age, while the twenties are the period of life which offers opportunities. Additionally, an extended period of freedom, a career and a feeling of a lack of psychological readiness may also be factors that promote late childbearing, and these determinants may be used to characterize approaches to life as well. The very different life strategies are seen as consequences of the growing variation in life's opportunities.

In the paper of Ravn and Lie (Chapter 6) the possible conflict between modern and non-modern values arises. The need to make a joint decision as a cultural unit about whether (and/or when) to have children can conflict with the growing importance of autonomy and individual choice. This suggests that, despite the fact that the concept of making a joint decision is culturally expected, children appear in both domains of choice: "the meaning of children emerges in the balance of child's place in individual life trajectories and the child as a symbol of togetherness" (p. 99).

Moreover, the notion of the 'right time' to have children is also discussed in this chapter, but not only from an individual perspective. Since one individual's 'right time' may differ from the right time of the other person in the relationship, the results underline the importance of the discussion of timing between partners. In this respect, class and gender differentiation are important, mainly because of a women's right to make a decision concerning her body, and also because upper middle class women often plan to secure their position in the labour market before having a child.

In the seventh chapter Bergnéhr and Bernhardt propose that modern expectations about the right to independence and individual self-fulfilment may conflict with the social meaning of children; this leads to the observation that having children today requires more time and energy than ever before 
in history. This creates ambivalence about childbearing decisions (based on quantitative data it is suggested that men are more likely to be ambivalent). Age and post-secondary education has an ambivalence-increasing effect, while living with a partner has the reverse impact - mainly for men. These qualitative findings show that 'modern' characteristics exist in the practice of childrearing: informants mentioned having new experiences and opportunities and describe childbearing as a self-fulfilling project. All in all, despite ambivalence among young adults, the authors that suggest having children brings them emotional benefits and is a natural step along the path of life.

Bernardi's (Chapter 10) findings about the intergenerational transmission of normative beliefs about fertility choices between mothers and their daughters contain two lines of continuity. First, the centrality of family interactions and strong beliefs about the role of women as mothers has an impact on fertility outcomes. Secondly, the centrality of the desire for self-realization and female autonomy are also bases for such continuity between generations. Consequently, the importance of research into fertility choices from a lifecourse perspective is highlighted.

Similarly to the notion of 'the right time', maturity and personal stability emerge as crucial to having children in this paper. Additionally, children are perceived as being fulfilling to individuals, and as the beginning of the creation of a family. The same idea also appears in previous chapters.

The investigation of gender aspects is outstanding in the book because, as mentioned above, the majority of the papers focus on gender differentiation. These differences are notably highlighted in the remaining two papers. Moreover, the role of fathers is also more emphasized in these chapters (Chapter 8, 9).

The comparison of two five-year cohorts in Norway (Lappegård et al. Chapter 9) indicates that regarding social differences, contrasting processes occur with men and women: the differences among men have become greater (particularly with regard to the widening gap in childlessness among different educational groups), whereas decreasing incidences of childlessness and higher fertility rates among women have resulted in their converging fertility patterns. Their findings outline the fact that significant numbers of mothers can also remain actively employed - mainly from the year after the birth of their child. This corresponds with the already-stated importance of the dual earner model both in France and in Norway. Moreover, it is underlined that fathers are much more strongly attached to labour markets than childless men. The authors argue that increasing childlessness among men implies that there is a stronger selection process that occurs into fatherhood than into motherhood (p. 150). Based on these differences the authors question the 
concept of the societal acceptance of gender equal parenthood.

The role of fathers also emerges in most of the papers in this book - Letablier maintains that there is no support for active fatherhood in French family policy, while in contrast the papers about the Nordic countries refer many times to the generous support given to fathers to promote gender equality in these states. Jensen's paper (Chapter 8) is the only one which places particular emphasis on men and therefore supplements these aforementioned findings and finds other explanations for the childlessness of men and to the father's role in childbearing.

The author also emphasizes the importance of personal relations. The main findings suggest that women's networks have more impact, and even for men the partner's network plays a significant role. However, children are part of a normative system; they are not a component of men's discussions and having a child leads to the weakening of relationships between male friends (the opposite is true for women). Additionally, social learning theory has relevance; watching friends with children is crucial for women and influences their timing and social life with children, and it also has a positive impact for men.

Working class men see having children as a natural stage of life, while upper middle class men feel more pressure - mainly from partners and their networks - although they also associate children with success and selffulfilment. Those who have no children report a feeling of lagging behind friends who do. In conclusion, while children are in the centre of women's networks, they are not a strong component of men's.

Jensen explains her results by referring to the one unexpected effect of family policies. This is that growing expectations about fatherhood from men and the demands of the workplace mean that men may associate fatherhood with risk. This is proven by the constantly higher employment rate of fathers and also may explain their growing childlessness. Bergnéhr and Bernhardt also have found that men are more ambivalent about parenthood than women.

The growing amount of research which has explored the work-life conflict of men supports this idea. Increasing gender equality and a revaluation of caring has resulted in greater childrearing responsibilities for fathers, which in turn has led to the emergence of new forms of fatherhood. The changes have created some new expectations for fathers which may conflict with the expectations of the labour market (Marks - Palkovitz 20044), a phenomenon which Jensen (p. 122) terms 'double demand'. However, although social

4 Marks, L. - Palkovitz, R. (2004): American Fatherhood Types: The Good, the Bad, and the Uninterested. Fathering, 2. (2): 113-129. 
policy initiatives are primarily aimed at supporting women's reconciliation of home and work, over the last decades fathers have also became a target group (Craig - Mullan, 2010 $)$. Accordingly, this book also attempts to contribute to the exploration of the situation concerning fatherhood in Europe today.

The volume under review is a fine example of how the fertility issue may be approached in ways other than by addressing the general decline in fertility and thus offers a more comprehensive understanding of the factors that define reproductive choices in Europe. Furthermore, the qualitative methods and diverse theoretical backgrounds which have been applied encourage more nuanced insight and enrich our knowledge about childbearing decisions.

Although the wide selection of countries and approaches enables comprehensive exploration of the economic and non-economic rationales in people's fertility choices in modern Europe, the inclusion of examples from the post-socialist countries would have moderated the economic analysis of childbearing.

Besides an investigation into the influence of class which improves the economic perspective of the book, the focus on gender differences reveals the fact that fertility is a matter not only for women and sheds some light on the emerging new ambivalences of fatherhood.

5 Craig, L. - Mullan, K (2010): Parenthood, Gender and Work-Family Time in the United States, Australia, Italy, France and Denmark. Journal of Marriage and Family, 72. (5): 1344-1359. 